\title{
COMMITTEE ON SMALL BODY NOMENCLATURE
}

\author{
(COMITÉ POUR LA NOMENCLATURE DES PETITS CORPS \\ CÉLESTES)
}

\author{
CHAIRWOMAN: P. Kilmartin \\ MEMBERS: M. A'Hearn, K. Aksnes, J. Fernández, D. Green, Y. Kozai, \\ B.G. Marsden, L. Schmadel, V. Shor, J. Tichá, R.M. West, G. Williams, D. \\ Yeomans, J. Zhu.
}

\section{Membership}

The committee met in two public sessions with 9 members present and up to 20 interested individuals. Apologies were received from L. Schmadel, V. Shor, J. Zhu and R. West. Membership was reviewed for the triennium 2003-2006. Ex officio members are I. Williams (UK) as incoming president of Division III, B.G. Marsden (USA) as director of the Minor Planet Center, and K. Aksnes (Norway) as president of the Working Group on Planetary System Nomenclature. Members elected for the next triennium are M. A'Hearn (USA), J. Fernández (Uruguay), P. Kilmartin (New Zealand), Y. Kozai (Japan), D. Lazzaro (Brazil), L. Schmadel (Germany), V. Shor (Russia), J. Tichá (Czech Republic), R.M. West (Denmark/ESO), G. Williams (USA), D. Yeomans (USA), J. Zhu (China), and D. Green (USA) as director of the Central Bureau for Astronomical Telegrams, for comet names only. J. Tichá was elected as incoming chairwoman of the committee. This membership was later presented to the Division III meeting.

\section{Dictionary of Minor Planet Names}

The fifth edition of the committee's official publication, the Dictionary of Minor Planet Names, was introduced by P. Kilmartin (the editor, L. Schmadel, unfortunately unable to be present). The new edition contains all names and citations of minor planets up to Dec. 2002. It will form the basic reference volume for minor planet names and their history. Supplementary booklets are planned to be published each General Assembly year, with new names assigned during the previous triennium. Discussion on the possibility of having names and citations available on the Internet resulted in general agreement that names/citations assigned since Dec. 2002 should be on the CSBN web page; and investigation should continue for posting all. It was thought desirable that all members of CSBN should have a copy of the Dictionary if the IAU can provide them.

\section{Satellites of Minor Planets}

K. Aksnes, president of the WGPSN, reported that the WG was in favor of the CSBN being responsible for names of minor planet satellites. It was agreed that with the agreement of the WGPSN, the CSBN will assume responsibility for the naming of satellites of minor planets. Expanding on past practice, satellites of minor planets will, where possible and appropriate, receive names closely related to the name of the 
primary and suggesting the relative sizes. For example, binary transneptunian objects of comparable size should receive the names of twins or siblings consistent with the current principle of using names of gods of creation or the underworld. The committee also agreed to give the name Linus to the satellite of (22) Kalliope (Linus in Greek mythology is reputed to be a son of Kalliope). Names of minor planet satellites would be announced in the IAU Circulars and approved by the WGPSN in its triennial lists and on its web page. Discoverers and others may suggest names but the committee should take care that current principles are followed.

\title{
4. Limiting of Names
}

Discussion continued in the CSBN since late 2001 on whether to limit the numbers of minor planets named, and how to do this if necessary. As a first step in this, it was agreed that the CSBN recognises the need to limit the numbers of minor planets named, and requests individual discoverers and teams to propose no more than 2 names each 2 months. It is understood by the committee that longer lists for special occasions could still be submitted, and may be accommodated at the committee's discretion.

\section{Diversity of Names}

J. Fernández again urged that efforts be made to increase the geographical diversity of names. B.G. Marsden remarked that the MPC frequently receives suggestions for names, often from countries from which no minor planets are discovered, but there is no resource to use these suggestions. A proposal that one per cent of each discoverer's total should be assigned to the CSBN for use in increasing the diversity was discussed; but it was concluded that the 10 year rule, if enforced, should already provide such a resource, and consideration of a one per cent tax should be delayed until there was a demonstrated need for it.

\section{Guidelines for Names}

Experience during 2000-3 had led to further calls for a written guideline on commercial names. The committee agreed that names honoring persons or companies or products for no more than success in business are discouraged; and names or citations that resemble advertising will not be accepted. B.G. Marsden said that there is as yet no theme for naming scattered-disk objects, and that there was a suggestion to use names from the books of Tolkien. No decision was reached on this.

\section{Credit for Citations}

D. Yeomans questioned the crediting in citations of their writers (when not the discoverer) and of endorsements of names. V. Shor, in a written communication, argued for allowing the practices to continue but within the 4 permitted lines. Others recommended flexibility as the proposer of a name may be of historic interest. A guideline saying that citation authors and endorsements of citations would not normally be appropriate was discussed.

\author{
P. Kilmartin \\ Chairwoman of the Committee
}

